Int. J. Environ. Sci. Tech.

(C) Summer 2005, Vol. 2, No. 2, pp. 169-173

\title{
Genotype and environment interaction effect on yield of cotton under naturally salt stress condition
}

\author{
${ }^{*}$ Y. Ali, Z. Aslam and F. Hussain
}

Nuclear Institute for Agriculture and Biology, P.O. Box-128, Faisalabad, Pakistan

\begin{abstract}
Thirteen genotypes of cotton developed through hybridization and mutation breeding techniques were evaluated during two consecutives years 2002-03-04 on eight locations covering most of the area of Punjab province including Faisalabad, Toba Tek Singh and Jhang. The eight sets of experiments were conducted in the naturally highly saline sodic soils, EC ranges from 7.8-36.1 d/Sm, $\mathrm{pH}=8.1-8.8$, SAR=10.1-40.5, Saturation percentage 31.3-40.8 and texture Sandy Clay loam and Clay loam. The seed yield data was collected at maturity and stability parameters were computed to know genotypic environment interaction and varietals performance. The combined analysis of variance showed highly significant variance in case of varieties, locations and varieties x environment (Lin) also showed highly significant differences. It means that genotypes exhibited different behavior in different locations/environments which is due to their different genetic make up. The behavior may be cross over (in which significant change in ranking order occurs from one environment to another) or cross over nature (in which case the ranking of genotypes remains constant across environments and the interaction is significant because of change in the magnitude of response) depending upon the ranking order of genotypes performance under different environments. In our study only S-12 behavior was of almost non cross over nature, while others had cross over type of interaction. Based on over all seed yield cotton variety NIAB999 and CIM-707 produced highest seed yield cotton (3.2 t/ha, 3.17t/ha). The lowest seed yield cotton was noted in S-12 (1.86 t/ha). All the three parameters of stability i.e. overall mean seed yield cotton, regression coefficient and standard deviation to regression provided clear evidence that variety NIAB-999 and CIM-707 produced maximum stable yield compared to S-12.
\end{abstract}

Key words: Cotton, environmental interaction, stability, genotypes, salinity

*Corresponding Author, E-mail: Yousaf_sem@yahoo.com

\section{Introduction}

Cotton (Gossypium hirsutum L.) is a major cash crop of Pakistan and is also grown on moderately saline soils where its yield and quality is much lower as compared to normal soils. It has played a significant role in industrial development and employment generation. It is known as backbone of Pakistan's agriculture, which is the backbone of Pakistan's economy. Its impact on the economic development of the country is well established and it is rightly known as the silver fiber of Pakistan. It occupies the $2^{\text {nd. }}$ position with respect to cultivated areas of all the crops in the country and is cultivated on an area of about $2.79 \mathrm{~m}$. ha (Anonymous, 2003). The development of new genotypes of a particular crop is a continuous need due to degeneration of genetic makeup because of appearance of new biotic and abiotic stresses.

Although cotton is considered as being fairly tolerant to salinity (Maas and Hoffman, 1977; Maas, 1986) yet its yield is drastically reduced due to poor germination and subsequent abnormal plant development under saline conditions (Khan, 1987). A decrease of about $41 \%$ in seed yield in slightly salt affected soils has been reported (Qayyum and Malik, 1988).

Cotton is quite sensitive to salinity at germination and seedling stages but comparatively tolerant there after (Bhatti and Rashid, 1980). Therefore the spotty pattern in crop stand at maturity under saline soil conditions is actually initiated at the time of germination and vegetative growth phase. Moreover build up of certain ions in the cytoplasm may affect certain metabolic processes. In saline soil, $\mathrm{Na}^{+}, \mathrm{K}^{+}$ and $\mathrm{Cl}^{-}$are the dominant ions affecting plant growth (Khan, 1987 and Maas, 1993). Under these conditions the activities of some essential nutrients may also be reduced (Gratten and Grieve, 1992) and plants may experience nutritional disorders.

It is now evident that some plant species can tolerate high salinity (Glenn, et al., 1996 and Rehman, et al., 1998). Significant differences in character have also been reported among varieties 
of different species including wheat (Akhtar, et al., 1994, 1998 and Saqib, et al., 1999) and cotton (Qadir and Shams, 1997 and Ashraf and Ahmad, 2000). The differential behavior of plant species may be helpful for exploitation of these soils by growing fairly tolerant genotypes.

The yielding ability of a variety is the result of its interaction with the prevailing environment. Environmental factors such as soil characteristics and types, moisture, sowing time, fertility, temperature and day length vary over the years and locations. There is strong influence of environmental factors during various stages of crop growth (Bull, et al., 1992), thus genotypes differ widely in their response to environments. Many research workers are of the view that average high yield should not be the only criteria for genotype superiority unless its superiority in performance is confirmed over different types of environmental conditions (Qari, et al., 1990; Kinyua, 1992; Golmirzaie, et al., 1990 and Liu et al., 1992).

Stability in performance of a genotype over a range of environments is a desirable attribute and depends upon the magnitude of genotype $\mathrm{x}$ environment interactions (Ahmed, et al., 1996).

In Pakistan, 6.8 mha of land is salt-affected. Out of this, 2.67 mha is in Punjab. Slightly saline land in Punjab is 472.4 , moderately saline 805 , severely saline 788 and very severe saline land is 652 thousand hectares (Anonymous, 2003). So there is dire need to screen cotton genotypes which have stable performance over range of salt affected lands. This will help a lot to improve and increase the cotton area and production. Keeping all these factors in mind, a multilocational experiments was designed to study the performance of diverse types of cotton genotypes over a range of salt affected lands. This study has been done in Nuclear Institute for Agriculture and Biology on 2003-2004.

\section{Materials and Methods}

In a multilocational experiment comprising 13 genotypes of cotton developed through mutation breeding and crossing techniques was evaluated during two consecutives years in summer season of 2002 and 2003. The experimental locations were spread at 8 sites in the districts of Faisalabad, Toba Tek Singh and Jhang. The experiment were conducted on the naturally high saline sodic soils with EC ranging from 7.8-36.1 d/Sm, $\mathrm{pH}=8.1-8.8$, and SAR $=10.1-40.5$. Saturation percentage, 31.340.8 and texture sandy clay loam and clay loam.
The seed yield data were collected at maturity and subjected to analysis of variance (Steel and Torrie, 1980) and stability parameters were computed following (Eberhart and Russell Model, 1966).

\section{Results}

Combined analysis of variance (Table 1) showed highly significant differences among varieties, environment and varieties $\mathrm{x}$ environments interaction. Highly significant difference in the genotypes of cotton under study may be due to differences in their genetic make up and diverse nature of origin. The highly significant differences in locations indicated an existence of variation in the prevailing environments. The highly significant genotype $x$ environment ( $\mathrm{G} \times \mathrm{E}$ ) interaction may be either a cross over $G \times$ E interaction or a non cross over nature. In crossover, significant change in ranks occurs from one environment to another (Matus, et al., 1997). In non cross over, $G \times x$ E interaction, ranking of genotypes remains constant across environments and the interaction is significant because of changes in the magnitude of response (Baker, 1988; Blum, 1983; Matus, et al., 1997). Genotypes showed highly significant differences in their mean seed yield performance. In this study, only S-12 almost showed non cross over nature G x $E$ interaction while other genotypes had cross over type of $\mathrm{G}$ x E interaction.

Varieties also showed highly significant differences in case of pooled analysis of variance (Table 2). Varieties x environments (linear) was nonsignificant and non linear (pooled deviation) also showed non-significant differences.

Highly significant differences are very important for determining G x E interaction. Relatively higher value of the linear component as compared to nonlinear one, suggested the possibility of prediction of performance for seed yield over the environments. High values of linear components as compared to non linear have been reported by many workers (Khan, et al., 1987; Yadav and Tomar, 1985 and Khan, 1988).

Over all mean seed yield performance (Table 3) showed significant differences. Variety NIAB-999 and CIM-707 produced significantly the highest seed cotton yield (3.21 t/ha) and (3.17 t/ha) respectively, followed by NIAB-86 (2.95 t/ha). The lowest performing genotype was S-12 (1.86 t/ha). This may be due to its more sensitiveness to salt and non adaptiveness in these conditions. S-12 showed highly significant while CIM-482 significantly difference 
of regression coefficient than unity. One out of thirteen genotypes under study showed highly significant and one significant difference from zero in case of standard deviation to regression coefficient (Table 3). Stability analysis has also been carried out in many crops such as wheat (Sial, et al., 2000), Oat (Helm, 1993) lentil (Sarwar, et al., 2003) and cowpea (Yousaf, et al., 2004).

\section{Discussion and Conclusion}

Regression coefficient (bi) is considered as parameter of response and $S^{2} d$ as the parameters of stability. For a given value of independent variable, the value for dependent variable may be estimated using the regression equation, provided $\mathrm{S}^{2} \mathrm{~d}$ is not significantly different from zero.

Table 1: Combined analysis of variance for cotton

\begin{tabular}{|clccccc|}
\hline Values & Source & $\begin{array}{c}\text { Degree of } \\
\text { freedom (d. ) }\end{array}$ & Sum of squares (s.s) & $\begin{array}{c}\text { Mean square } \\
(\mathrm{m} . \mathrm{s})\end{array}$ & F value & Prob. \\
\hline 1 & Replication & 2 & 0.107 & 0.054 & $5.4544^{* *}$ & 0.0049 \\
2 & Factor A & 12 & 30.371 & 2.561 & $260.8827^{* *}$ & 0.0000 \\
4 & Factor B & 7 & 10.139 & 1.448 & $147.5516^{* *}$ & 0.0000 \\
6 & AB & 84 & 4.701 & 0.056 & $5.7009^{* *}$ & 0.0000 \\
7 & Error & 206 & 2.022 & 0.018 & & \\
& Total & 311 & 47.700 & & & \\
\hline
\end{tabular}

Table 2: Pooled analysis of variance for cotton

\begin{tabular}{|lcccc|}
\hline \multicolumn{1}{|c}{ Source } & $\begin{array}{c}\text { Degree of } \\
\text { freedom (d.f) }\end{array}$ & $\begin{array}{c}\text { Sum of squares } \\
\text { (s.s) }\end{array}$ & $\begin{array}{c}\text { Mean square } \\
\text { (m.s) }\end{array}$ & F. Value \\
\hline Total & 103 & 15.188 & 0.147 & \\
Environments & 7 & 3.379 & 0.483 & $55.954^{* *}$ \\
Varieties & 12 & 10.242 & 0.854 & \\
Varieties x Environment & 84 & 1.567 & 0.019 & \\
Environment + Varieties x Environment & 91 & 4.945 & 0.054 & $2.059 *$ \\
Environment (Lin) & 1 & 3.379 & 3.379 & \\
Varieties x Environment (Lin) & 12 & 0.377 & 0.031 & 1.525 \\
Pooled Deviation & 78 & 1.190 & 0.015 & \\
Pooled Error & 208 & 2.080 & 0.010 & \\
\hline
\end{tabular}

Table 3: Stability parameter of cotton genotypes tested under various environments

\begin{tabular}{|clccc|}
\hline Sr. \# & $\begin{array}{c}\text { Variety/Mutant } \\
\text { Name }\end{array}$ & $\begin{array}{c}\text { Mean Seed Yield } \\
\text { (ton/ha) }\end{array}$ & $\begin{array}{c}\text { Regression co-efficient } \\
(\mathrm{bi})\end{array}$ & $\begin{array}{c}\text { Standard deviation to regression } \\
\left(\mathrm{S}^{2} \mathrm{~d}\right)\end{array}$ \\
\hline 1 & NIAB-86 & $2.947 \mathrm{~B}$ & 1.507 & $0.072^{* *}$ \\
2 & NIAB-111 & $2.682 \mathrm{C}$ & 0.995 & 0.010 \\
3 & NIAB-999 & $3.210 \mathrm{~A}$ & 1.019 & $0.024^{*}$ \\
4 & Strain PIM-80 & $2.635 \mathrm{C}$ & 0.489 & 0.020 \\
5 & CIM-499 & $2.616 \mathrm{C}$ & 0.985 & 0.011 \\
6 & NIAB-98 & $2.682 \mathrm{C}$ & 0.843 & 0.009 \\
7 & Strain PIM-81 & $2.646 \mathrm{C}$ & 1.064 & 0.004 \\
8 & CIM-473 & $2.650 \mathrm{C}$ & 0.993 & 0.008 \\
9 & CIM-446 & $2.666 \mathrm{C}$ & 1.228 & 0.003 \\
10 & CIM-497 & $2.662 \mathrm{C}$ & 1.158 & 0.002 \\
11 & CIM-482 & $2.671 \mathrm{C}$ & $1.301^{*}$ & 0.003 \\
12 & CIM-707 & $3.174 \mathrm{~A}$ & 1.241 & 0.020 \\
13 & S-12 & $1.855 \mathrm{D}$ & $0.177^{* *}$ & 0.011 \\
\hline
\end{tabular}


Assuming $\mathrm{S}^{2} \mathrm{~d}=0$, a high value of bi will mean more change in y for a unit change in (bi) In other words, the variety is more responsive. Such variety may, therefore, be recommended only for highly favourable environments, say under high fertility conditions. A relatively lower value of bi, say around 1 , will mean less responsive to the environmental change and therefore, more adaptive. If, however, bi is negative the variety may be grown only in poor environment. $S^{2} d$, if significant from zero, will invalidate the linear prediction. If $\mathrm{S}^{2} \mathrm{~d}$ is non significant, the performance of a genotype for a given environment may be predicted. Accordingly, a variety whose performance can be predicted (i.e. $\mathrm{S}^{2} \mathrm{~d}=0$ ) is said to be stable. Here stability means predictability. Mutant variety NAIB-999 showed highly significant regression coefficient differences from unity. Compared to this variety CIM-707 exhibited non significant difference of regression coefficient from unity. Variety CIM-707 also showed non significant differences of standard deviation to regression coefficient from zero. All the three parameters of stability i.e. overall high mean seed yield, regression coefficient and standard deviation to regression, provided clear evidence that variety NIAB- 999 and variety CIM-707 produced maximum stable yield compared to S-12. From these results of stability it may be concluded that in such type of saline soils as studied here, the newly evolved mutant line NIAB-999 and CIM-707 may be grown safely for obtaining more economical yield potential without facing any major drawback of adaptation to this particular saline area. Furthermore, these studies provided a clue that breeding techniques other than conventional (mutation breeding) could be successfully employed for the induction of variation to select the new genotypes with improved agronomic and physiological characters suitable for stress environment like salinity.

\section{References}

Ahmad, J., M. H. Chaudhry, S. Salah-ud-Din and M. A. Ali, Stability for grain yield in wheat. Pak. J. Bot., 28: 61-65, 1996

Ali, Y., Z. Aslam, F. Hussain and A. Shakur, Genotypic and environmental interaction in cowpea (Vigna unguiculata L.) for yield and disease resistance. Internal. J. Environ. Sci. Tech, 1(2): 127-131, 2004

Akhtar, J., J. Gorham and R. H., Qureshi. Combined effect of salinity and hypoxia in wheat (Triticum aesitivum
L) and wheat-Thinopyrum amphiploids. Plant soil166-47-54, 1994

Akhtar, J. J. Gorham, R. H. Qureshi and M. Aslam. Dose tolerance of wheat to salinity and hypoxia come late with root dehydrogenize activities or parenchyma formation plant soil. 201: 275-284, 1998

Anonymous, Agricultural statistics of Pakistan. Government of Pakistan, Ministry of Food, Agriculture and Live Stock, Economic Wing, Islamabad, (83-84), 2003

Ashraf, M. and S. Ahmad, Influence of sodium chloride on ion accumulation, yield components and fiber characteristics in salt tolerant and salt sensitive lines of cotton (Gossypium hirsutum L). Field crops res., 66: 115-127, 2000

Baker, R. J., Test for crossover genotype-environmental interaction. Can. J. Plant Sci., 68: 405-410, 1988

Bhatti, H. M. and M. Rashid, Role of soil factors in cotton production. A review. The Pak. Cotton. 24: 183-192, 1980

Blum, A. Genetic and physiological relationship in plant breeding for drought resistance. In: Plant production and management under drought conditions (Eds.): J. T. Stone and W. O. Willis. Elsevier Amsterdam., 195205, 1983

Bull, J. K., M. Cooper, I. H. Delacy, K. E. Bassford and D. $R$. Woodruff, Utility of repeated checks for hierarchical classification of data from plant breeding trials. Field Crop Res., 30:79-95, 1992

Eberhart, S. and W. A. Russell. Stability parameters for comparing varieties, Crop Sci., 6: 36-40, 1966

Glenn. E. R. Pfister, J. J. Brown, T. L. Thompson, J. W. O. Leary, $\mathrm{Na}$ and K accumulation and salt tolerance of Atriplex canescens (Chenopodiaceae) genotypes. Am. J. Bot., 83: 997-1005, 1996

Gratten, S. R. and C. M. Grieve, Mineral element acquisition and growth response of plant grown in saline environments. Agri. Ecosystems Environ, 38: 275-300, 1992

Golmirzaie, A. M., J. W. Schmidt and A. F. Dreier, Components of variance and stability parameters in studies of cultivars $x$ environment interaction in winter wheat (Triticum aestivum L.), Cereal Research Communications, 18: 249-256, 1990

Helms, T. C., Selection for yield and stability among oat lines. Crop Sci., 33: 423-426, 1993 
Khan, A. N., Mechanisms of salt tolerance in cotton. PhD. Thesis, Dept. soil Sci, Univ. Agric. Faisalabad, Pakistan, 1987

Khan, I. A., B. A. Malik and M. Bashir, Investigation of genotype x environment interaction for seed yield in chickpea (Cicer arietinum L.) Pak. J. Bot. 20:201204, 1988

Khan, I. A., B. A. Malik and M. Tahir, Phenotypic stability for yield in chickpea. Pak. J. Sci. Ind. Res. 309: 455456, 1987

Kinyua, M. G., Genotype x environment effects on bread wheat grown over multiple locations and years in Kenya. In: $7^{\text {th. }}$ regional wheat workshop for Eastern, Central and Southern Africa Nakuru Kenya, 103-107, 1992

Liu, L. X., T. C. Haung, G. T. L. Liu and S. Z. Zhang, Stability analysis of yield and quality characters of hybrid and pure line winter wheat cultivars. Acta. Agronomica Sinica., 18: 38-49, 1992

Maas, E. V. and G. J. Hoffman, Crop salt tolerance current assessment. J. Irrig. Drainage Div., 103: 115-134, 1977

Maas, E. V., Salinity and citriculture. Tree physiol., 12: 195-216, 1993

Maas, E. V., Salt tolerance of plants. App. Agric. Res., 1: 12-26, 1986

Matus, A., A. E. Slinkard and C. V. Kessel, Genotype x environment interaction for carbon isotope discrimination in spring wheat. Crop Sci., 37: 97102, 1997

Qadir, M. and M. Shams, Some agronomic and physiological aspects of salt tolerance in cotton (Gossypium hirsutum L.) J. Agron. Crop sci., 179: 101106, 1997
Qari, M. S., N. I. Khan and M. A. Bajwa, Comparison of wheat cultivars for stability in yield performance. Pak. J. Agri. Res., 11:73-77, 1990

Qayyum, M. A. and D. Malik, Farm production losses in salt affected soils. In managing soil resources proc.

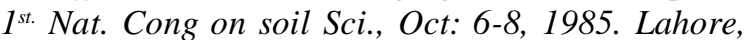
Pakistan, 356-364, 1988

Rehman, S., P. J. C. Harris and W. E. Bourne, The effect of sodium chloride on the $\mathrm{Ca}^{++}, \mathrm{K}^{+}$and $\mathrm{Na}^{+}$ concentration of the seed coat and embryo of Acacia tortilis and A. cortacea. Ann. Appl. Biol., 133: 269279, 1998

Saqib, M., R. H. Qureshi, J Akhtar, S. Nawaz and M. Aslam, Effect of salinity and hypoxia on growth and ionic compositions of different genotypes of wheat. Pak. J. Soil Sci., 17: 1-8, 1999

Sarwar, G., M. S. Sadiq, M. Saleem and G. Abbas, Genotype $x$ environment interaction in newly developed lentil germplasm under cotton based cropping system. Proc. of Seminar "Sustainable utilization of plant genetic resources for agricultural production”, 17-19 Dec, 2002, NARC Islamabad, 219226, 2003

Sial, M. A., M. A. Arain and M. Ahmad. Genotype x environment interaction on bread wheat grown over multiple sites and years in Pakistan. Pak. J. Bot., 32: 85-91, 2000

Steel, R. G. D., and J. H. Torrie, Principles and Procedures of Statistics. McGraw Hill Book Company, Inc. New York, 1980

Yadav, R. S. and P. S. Tomar, Protein content and stability in black gram. Ind. J. Agri. Sci., 55: 510512, 1985 